\title{
Performance of a Heavy-Duty Turbocharged Diesel Engine Under the Effect of Air Injection at Intake Manifold During Transient Operations
}

\author{
S. M. Saad ${ }^{1,2} \cdot$ R. Mishra ${ }^{1}$ \\ Received: 27 June 2018 / Accepted: 2 February 2019 / Published online: 15 February 2019 \\ (c) The Author(s) 2019
}

\begin{abstract}
The effectiveness of an air injection technique for the improvement in transient response of heavy-duty turbocharged diesel engines has been investigated but only to a limited extent. In the present work, the investigations are performed to improve the response characteristic of a heavy-duty turbocharged diesel engine under the transient event of rapid acceleration at low engine speeds. The engine model is developed using Ricardo wave software; and after the validation with the data obtained from the real engine, wave model is used to investigate the effectiveness of an air injection system for the improvement in performance of turbocharged diesel engine. The effect of air injection is observed by varying the air injection pressure and the time of acceleration. The turbocharger's response parameters such as the compressor exit pressure, turbine inlet temperature and turbine inlet pressure have been monitored to quantify the turbocharger lag. A pressure value of 1 bar is found to be the optimum injection pressure value that significantly reduces the turbocharger lag corresponding to all the selected parameters. Furthermore, faster recovery time is observed for the tests with $1 \mathrm{~s}$ duration of acceleration than that with $2 \mathrm{~s}$ duration of acceleration. Turbo lag reduction in percentage per unit energy is found to be $29.0 \%, 39.2 \%$ and $55.5 \%$ per Joule based on compressor exit pressure, turbine inlet pressure and turbine inlet temperature, respectively, at $1 \mathrm{bar}$ of air injection pressure.
\end{abstract}

Keywords Turbocharged diesel engine $\cdot$ Air injection $\cdot$ Transient response $\cdot$ Rapid acceleration $\cdot$ Wave model validation

$\begin{array}{ll}\text { Definitions/abbreviations } \\ \text { AFR } & \text { Air-to-fuel ratio } \\ \text { BMEP } & \text { Break mean effective pressure (bar) } \\ \text { IMEP } & \text { Indicated mean effective pressure (bar) } \\ \text { FMEP } & \text { Friction mean effective pressure (bar) } \\ \text { BSFC } & \text { Brake specific fuel consumption (kg/kW h) } \\ \text { CI } & \text { Compression ignition } \\ \text { CEP } & \text { Compressor exit pressure (bar) } \\ \text { TIP } & \text { Turbine inlet pressure (bar) } \\ \text { TIT } & \text { Turbine inlet temperature }(\mathrm{K}) \\ \text { TL } & \text { Turbo lag (s) } \\ D & \text { Cylinder bore (mm) } \\ P & \text { Cylinder pressure (bar) } \\ T & \text { Cylinder temperature (K) } \\ v_{\mathrm{c}} & \text { Characteristic velocity } \\ C_{\mathrm{enht}} & \text { User entered multiplier }\end{array}$

S. M. Saad

Syed.Saad@hud.ac.uk

1 University of Huddersfield, Queensgate, Huddersfield HD1 3DH, UK

2 Ibra College of Technology, Ibra, Sultanate of Oman

$\begin{array}{ll}P 1 & \text { Pressure before the orifice (bar) } \\ P 2 & \text { Pressure after the orifice (bar) } \\ A & \text { Orifice area }\left(\mathrm{mm}^{2}\right) \\ T^{\prime} & \text { Gas temperature at the orifice inlet }(\mathrm{K}) \\ R & \text { Gas constant }(\mathrm{kJ} / \mathrm{kg} \mathrm{K}) \\ \gamma & \text { Ratio of specific heats } \\ \dot{m} & \text { Mass flow rate of the air passing through the ori- } \\ \rho & \text { fice }(\mathrm{kg} / \mathrm{s}) \\ & \text { Air density }\left(\mathrm{kg} / \mathrm{m}^{3}\right)\end{array}$

\section{Introduction}

Diesel engines are also known as compression ignition (CI) engine due to its operating principle. During the compression stroke, the ignition of fuel takes place in the combustion chamber under the high-pressure and temperature conditions. In turbocharged diesel engines, the problem of turbo lag arises during the transient operating conditions. This problem arises from the lack of air induction due to the slower response of the turbocharger during a transient. To meet the requirement of complete combustion, sufficient air should be 
supplied to the engine. Hence, a good air injection system is important to achieve higher diesel engine performance [1].

The developments in CI engine technologies have led to the increase in the demand of fossil fuels causing the rapid depletion of fossil fuels reserves [2]. Recent estimates for fossil fuel predict that the fossil fuels may be completely depleted in the coming 45 years [3]. Fuel saving in the transportation sector is a critical issue across the globe [4]. In addition, the transport sector is undergoing rapid transformation due to stringent emission regulations in most of the developed countries with a target of improving fuel efficiency of the vehicles [5,6]. Turbocharging is considered as the most common boosting method used in the automotive industry. The reliability, widespread availability and excellent thermal efficiency of turbocharged diesel engine make them the prime mover for small and medium sized vehicles [7].

In turbocharged diesel engines, the heat that is generally lost in exhaust gases is recovered for compressing the fresh air into the engine cylinders. Turbocharger boosts the power output of the engine with the same displacement volume of the engine by providing intake air with increased density and hence increased mass. At high load transient conditions, faster response of the turbocharger is needed for the improvement in the drivability of vehicles with diesel engines. However, turbochargers have their own inefficiencies and there are associated problems such as the turbo lag. The turbo lag refers to the time required for the exhaust system and turbocharger to generate the required boost. When sudden load change is applied at lower engine speeds with rapid acceleration, the turbocharger must also accelerate to its new steady state. But the turbocharger does not respond effectively as compared to its naturally aspirated counterparts. The reasons for turbo lag are the inertia of the turbocharger rotor and the compressibility of exhaust gas within the engine [8]. Diesel engine performance is mostly influenced by turbo lag $[9,10]$. It leads to poor in-cylinder physical condition which causes deterioration of fuel economy and pollutant emissions [11-13].

Turbo lag is a common phenomenon in turbocharged diesel engine, especially during the rapid transient conditions. For the improvement in transient response of turbocharged engine, the reduction in turbo lag is considered vital. So far, three main technologies have been used for the reduction in turbo lag: electric torque assistance, air injection system and by the method of reducing the inertia of the compressor.

Lee and Choi [14] performed an experimental study to investigate the effect of air injection into the intake manifold. Air injection into the intake manifold during the rapid acceleration greatly improves the combustion performance of turbocharged diesel engine. The work is performed by physical testing which is costly and time-consuming. Air injection technology is still under development, and there are some technological challenges that encourage further investigations to be performed. The findings of simulation based investigations are equally important to model the optimal real systems.

The transient response can be improved by reducing the inertia of the compressor. In a study by Gilkes [15], the inertia values corresponding to the original compressor were systematically varied and their effect on turbo lag was analyzed. The pressure response of turbochargers with different inertia values is quantitatively analyzed, and the result shows that delay in the turbocharger response is reduced by reducing the inertia of compressor. Moreover, they compared the active method of injecting air into the inlet manifold and passive method of reducing the inertia of the compressor wheel and the results show that both methods reduce turbo lag; however, the active system produces superior results. But the turbo lag reduction achieved by this method is found to be very small. Moreover, reductions in inertia are difficult to achieve in practice.

During the operation of CI engines, the air-fuel ratio should be maintained within tight limits to obtain maximum engine output. During the turbo lag, this ratio changes and hence the quantity of air available may not be sufficient to meet the torque demand. During the period of low speed and fast acceleration, the air can be injected using different strategies to improve the air supply during transient operation of the turbocharger. Gilkes et al. [16] analyzed the effect of injecting air either at the inlet manifold or at compressor or simultaneously both at the manifold and compressor which is also known as two-point injection system. They performed a parametric study analyzing four parameters that are vehicle speed, outlet pressure of compressor, turbine inlet temperature and driver demand. It is found that the transient response of the turbocharger as well as the overall performance of the engine was improved using air injection systems. With air injection system, the turbo lag is reduced by $71 \%$ in achieving the vehicle response of $30 \mathrm{~km} / \mathrm{h}$. However, two-point air injection has shown small improvement.

A common rail direct injection (CRDI) engine was taken into consideration for air flow rationalization as well as turbo lag reduction [17]. The authors proposed a strategy for air injection directly into the combustion chamber. Accumulator and pressure regulator valve are the two additional components in the proposed system. At high engine speed and low torque demand conditions, the pressure regulator allows the high-pressure air in the inlet manifold to flow into the accumulator, to be stored there for later use during the turbo lag. So, during low inlet manifold pressure when the torque demand is high, the pressure regulator valve allows the air flow from the accumulator to the inlet manifold. Hence, the accumulator supplies the air according to the torque demand and balances acceleration and deceleration. 
Ceislar [18] examined the effect of air injection at various locations within the engine system and compared the results to establish the optimal injection location. The results revealed that air injection at exhaust manifold overcomes the problem of compressor surge while improving the transient response. In this investigation, the air injected at exhaust manifold is adjusted by a control valve and is stored in a compressed gas tank. The gas tank is recharged during the engine overrun when the pressure in the exhaust manifold is high. So, the compressed gas is collected in the tank during braking to be used later for assistance during a tip-in (acceleration phase). The system design for this functionality is very simple as it requires only a compressed gas tank, an additional exhaust manifold connection and a control valve. Standard dieselEGR/VGT is included in engine air path for the braking exhaust energy storage (BREES). The transient response of BREES is analyzed when the turbo lag is more pronounced, i.e., in high gears. The study concluded that this strategy of air injection offers better transient performance than intake manifold. Furthermore, larger amount of air can be injected without exceeding compressor surge limit. It is worth noting that time to torque during third gear tip-in acceleration is reduced by $60 \%$. However, the recharging of BREES is slow, demanding the clutch to be disengaged for about $3 \mathrm{~s}$. Also, the volume of gas tank is relatively large for automotive applications.

Computer simulations play important role in predicting the performance of engine systems. Lotus Engine Simulation Software is used in a study by Mishra and Saad [8] to perform investigations for the transient response of the turbocharged diesel engine under the transient event of rapid change in fueling rate. Findings indicate that with torque assistance, the transient response of the engine is significantly improved.

In a recent study by Giakoumis and Tziolas [19], a GT-Power model is constructed for a variable geometry turbocharged (VGT) truck diesel engine. Turbocharger as well as engine performance parameters are investigated. The study highlights benefit of VGT as compared to fixed-geometry operation in terms of higher boost pressure and air supply to the engine cylinders. An instrumental test bed was set up by Rakopoulos et al. [20] to investigate the key engine and turbocharger parameters. A variety of starting conditions are taken into consideration. The results indicate that turbo lag is the major contributor for increased pollutant emissions in all the cases.

The effect of oxygenated fuels on engine performance under transient and steady-state conditions is studied by Zare et al. [21]. Engine performance parameters were monitored during acceleration, load increase and steady-state operation conditions on a custom test setup. The study shows that the engine behavior during transient operation is different from steady-state operation. Comparing the oxygenated fuels with that of diesel, lower IMEP, BMEP and FMEP were observed.
Higher indicated torque, maximum in-cylinder pressure and maximum rate of pressure rise are found with oxygenated fuel during transient operation. However, during steady state, these three parameters are found to be lower for oxygenated fuels.

In another study by Zare et al. [22], effect of oxygenated fuels on transient and steady-state performance is investigated on both hot-start and cold-start operations of diesel engine. The study concludes that the increasing or decreasing trend of different parameters while changing the fuel cannot be determined by only one fuel property. Rather, it depends on conditions such as hot start or cold start.

Fang [1] employed air injection technique to improve the turbocharger response of marine diesel engine. The results of the study demonstrate that additional air injection helps to stop a marine engine faster, in case of sudden danger.

In most of the literature reviewed, the investigations are undertaken for light-duty and medium-duty vehicles. However, the effect of air injection on the response of heavy-duty vehicles is scarcely reported. Therefore, the objective of this study is to investigate the effect of air injection at intake manifold on the response of heavy-duty engine under the transient condition of rapid acceleration and more specifically to assess the potential improvements in the response of turbochargers. Furthermore, it is proposed to quantify the effects of acceleration time and injection pressure on the turbo lag.

In the present study after validating the Ricardo wave model with the real engine, additional air is injected at intake manifold to enhance the inlet mass flow rate at the moment of engine acceleration. This optimizes the combustion process inside the cylinder and produces increased torque output, therefore managing the problems caused by the turbo lag.

\section{System Modeling}

Currently within the engineering sector in particular, computer simulations are gaining widespread attention to model complex real-world problems which otherwise require expensive experimental setups. Ricardo wave is a $1 \mathrm{D}$ engine and gas dynamic simulation software package commonly used worldwide. In this model, the combustion process is modeled by Diesel Wiebe combustion model, which is an appropriate heat release model. For heat transfer process, the Woschni correlation model is used. The Woschni model expresses the convective heat transfer coefficient as given by Eq. (1) [23]:

$h_{\mathrm{g}}=0.0128 D^{-0.20} P^{0.80} T^{* 0.53} v_{\mathrm{c}}^{0.80} C_{\text {enht }}$

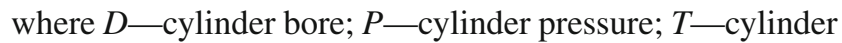
temperature; $v_{\mathrm{c}}$ - characteristic velocity; $C_{\mathrm{enht}}$ - user entered multiplier (For diesel jet combustion sub-model $C_{\text {enht=1 }}$ ). 
Table 1 Engine block specifications

\begin{tabular}{ll}
\hline Engine type & 4 stroke diesel \\
Stroke & $132 \mathrm{~mm}$ \\
Bore & $103 \mathrm{~mm}$ \\
Number of cylinders & 4 \\
Combustion system & Direct injection \\
Compression ratio & $18.3: 1$ \\
Connecting rod & $144 \mathrm{~mm}$ \\
Displacement & $4.399 \mathrm{~L}$ \\
\hline
\end{tabular}

In the present study, a four cylinder, four stroke, turbocharged diesel engine available at the Advanced Automotive Laboratory of University of Huddersfield, UK, is used to validate the engine model constructed using Ricardo wave simulation software. The description of the diesel engine is provided in Table 1. The engine specifications provided are applicable to heavy-duty diesel engine [24].

Wave build is a GUI interface to build a wave model. A fully connected turbocharged engine model is shown in Fig. 1. Elements representing the different engine components are connected by ducts. The components are available
Table 2 Basic valve parameters

\begin{tabular}{ll}
\hline Intake valves per cylinder & 2 \\
Intake valve diameter & $36.2 \mathrm{~mm}$ \\
Exhaust valves per cylinder & 2 \\
Exhaust valve diameter & $33.5 \mathrm{~mm}$
\end{tabular}

in the elements menu, and they are dragged from the menu to construct the model as per the requirement. Cylinders are selected from the flow element, and as per Table 1, bore is taken as $103 \mathrm{~mm}$, stroke as $132 \mathrm{~mm}$ and compression ratio as 18.3:1. For intake and exhaust valves, the basic valve parameters are entered as shown in Table 2 [25]. The intake and exhaust manifolds are modeled using ambient, ducts, orifices and junctions.

From the engine general panel, engine type is chosen as diesel and the specifications are entered as described in Table 1. Diesel Wiebe is chosen as the combustion model, and Woschni model is chosen for heat transfer. Fuel injectors are added to the model. From the turbo junction flow element, compressor and turbine are added on the canvas and a turbo shaft is selected from the mechanical element to con-

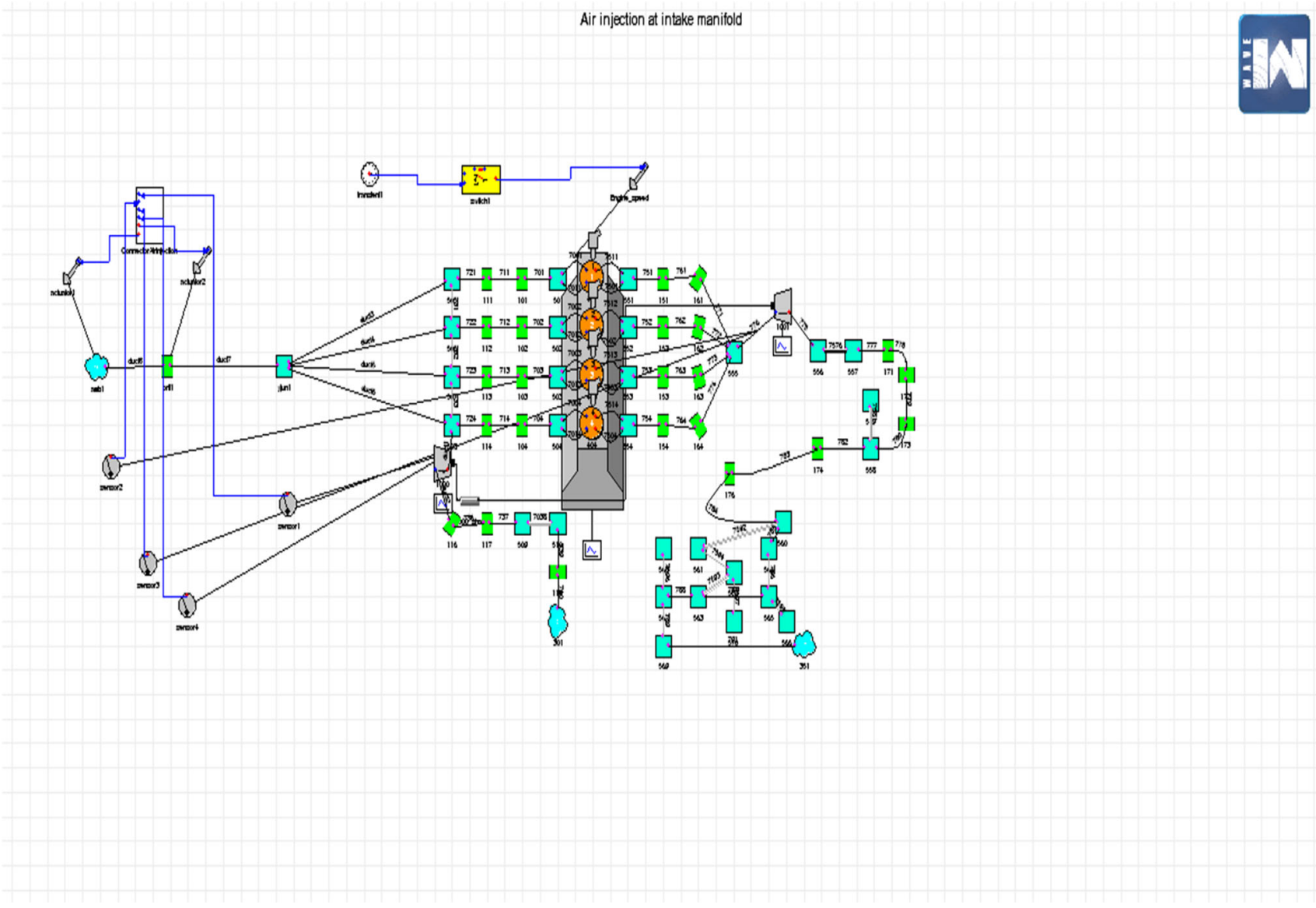

Fig. 1 Turbocharged engine model 
Fig. 2 Wave coupled Simulink model

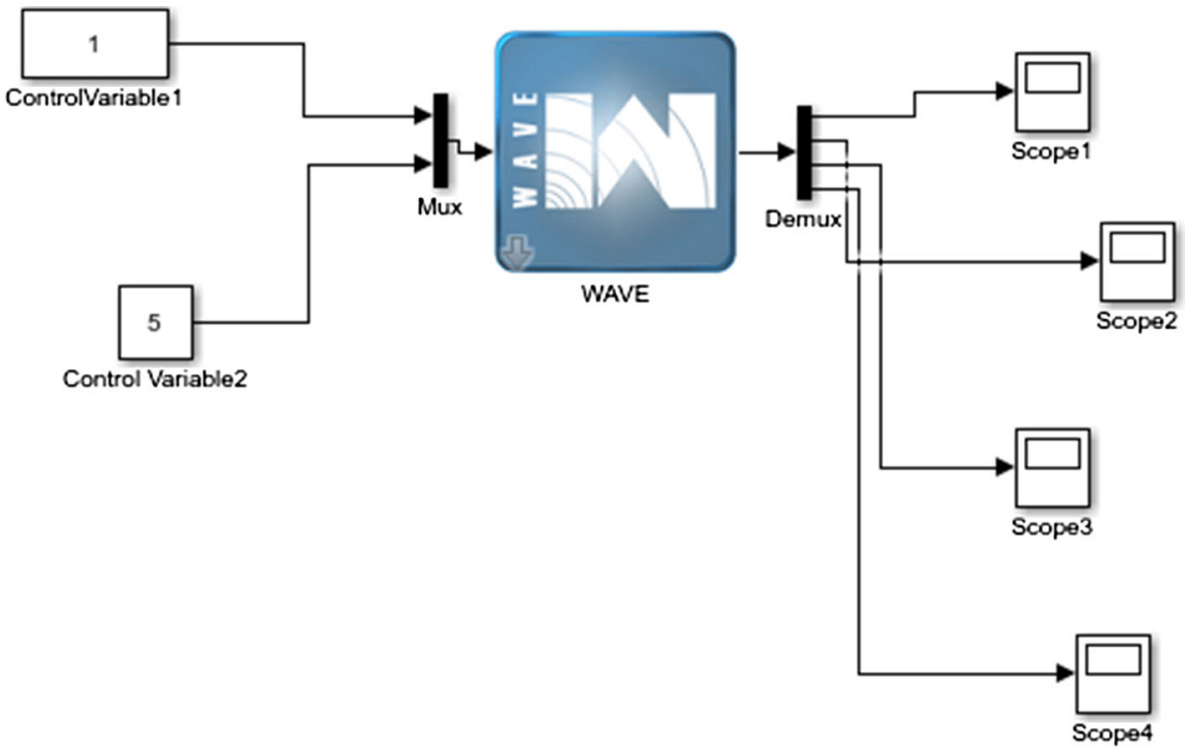

$\dot{m}=\frac{A P_{1}}{\sqrt{R T^{\prime}}} \Psi\left(\frac{P_{1}}{P_{2}}\right)$

to the intake manifold, and the turbine is connected with the exhaust manifold. Turbocharger is modeled with its performance maps. Ricardo wave provides preprocessed standard compressor and turbine map files that are used in the present investigations [23]. The maps consist of a four-dimensional dataset: rotational speed, mass flow rate of the gas, pressure ratio and efficiency. The performance maps need preprocessing before they can be used by WAVE. There exists a routine in WAVE Build that has an algorithm to convert a performance map into a TCMAP object that WAVE uses to model both the compressor and the turbine.

\subsection{Control System}

To regulate the air injection pressure, a control system is constructed using Simulink. Ricardo wave software has limited control system capabilities when compared to other dedicated control packages such as Simulink. However, the wave package includes an interface to Simulink [26]. The control system in Simulink coupled with wave model is shown in Fig. 2. Simulink accesses the wave signal through sensors and actuators. Signals from the sensors are sent "Out of WAVE," whereas the signals to the actuators are sent "Into WAVE." In Simulink, Mux block is used to create a vector of input signals, while the Demux block is used to split the vector of output signals [23].

The air injection system is modeled by the addition of third ambient. Air is supplied through an extra ambient into the intake manifold. The mass flow of air is regulated by an orifice. The air with injection pressure $P_{1}$ is passed through an orifice, and the mass flow of air through the orifice can be computed using Eq. (2) as given below [18]: where $\Psi$ is defined as:

$\Psi\left(\frac{P_{1}}{P_{2}}\right)=\left(\sqrt[\gamma]{\frac{P_{2}}{P_{1}}}\right) \sqrt{\left\{\frac{2 \gamma}{\gamma-1}\left(1-\sqrt[\gamma]{\frac{\gamma}{P_{1}}}\right)\right\}}$,

$$
\text { for } \frac{P_{2}}{P_{1}}>0.528
$$

$\Psi\left(\frac{P_{1}}{P_{2}}\right)=\left(\frac{2 \gamma}{\gamma-1}\right)\left(\frac{\gamma+1}{2(\gamma-1)}\right) \sqrt{\gamma}, \quad$ for $\frac{P_{2}}{P_{1}} \leq 0.528$

where $P_{1}$-pressure before the orifice; $P_{2}$-pressure after the orifice; $A$-orifice area; $T$-gas temperature $(\mathrm{K})$ at the orifice inlet; $R$-gas constant; $\gamma$-ratio of specific heats.

The energy supplied/sec through air injection can be calculated as: $\dot{\mathrm{E}}=\frac{P_{1} \dot{\mathrm{m}}}{\rho}$, where $\dot{m}$ is the mass flow rate of the air passing through the orifice and $\rho$ is the air density.

\section{Results}

The results obtained after carrying out simulations of the proposed system over a wide range of operating conditions are presented here. Real engine is simulated using Ricardo wave for steady-state and transient operating conditions. Based on the experimental data for steady state, the Ricardo wave model is calibrated for engine performance parameters such as brake torque, Brake specific fuel consumption, brake power and brake thermal efficiency. The wave model is then modified to include air injection system at intake manifold. The control system is formulated using the co-simulation 
of Ricardo wave with Simulink. The investigations are performed for various turbocharging parameters.

\subsection{Validation with Real Engine}

Steady-state testing is a useful tool for cross-checking the available measurements in addition to the verification of experimental setup. The test results for the steady state are collected from the real CI engine, and these results are used to validate the Ricardo wave model. It is assumed that the $1 \mathrm{D}$ gas dynamic code used in Ricardo wave has sufficient prediction capabilities to yield the reliable results. The nominal working range of the engine used in the investigations is 1000$2200 \mathrm{rpm}$. Engine performance parameters are chosen for validation of Ricardo wave model with the real data. They are:

1. Brake torque

2. Brake specific fuel consumption (BSFC)

3. Brake power and brake thermal efficiency

The validation of different engine performance parameters as a function of engine speed is shown in Fig. 3a-c. Figure 3 a depicts that initially torque rises at low engine speeds and attains the maximum value of $476 \mathrm{Nm}$ at $1200 \mathrm{rpm}$ and then gradually decreases with the increase in engine speed. Ricardo wave data have been analyzed using nonlinear regression, and the following equation has been obtained with $R^{2}=0.99$

$T=4 E-07 S^{3}-0.002 S^{2}+3.3208 S-1276.4$

where $T$ is the brake torque and $S$ is the engine speed in $\mathrm{rpm}$. Brake torque values using the equation above and those obtained from the experimental data have been plotted. It can be clearly observed from Fig. 3a that the predicted values of brake torque by Ricardo wave model are in good agreement with the experimental data.

Similarly, BSFC values predicted by Ricardo wave model can be described by the following equation with $R^{2}=1.0$ :

$$
\begin{gathered}
F=E-13 S^{4}-7 E-10 S^{3}+2 E-06 S^{2} \\
-0.002 S+1.02
\end{gathered}
$$

where $F$ is the brake specific fuel consumption and $S$ is the engine speed in rpm. Calculated values of BSFC were also satisfactory as shown in Fig. 3b. The validation of Ricardo wave with experiment shows a good agreement between the regression line values and experimental data for BSFC. The increase in fuel consumption at lower engine speed is due to the increased time for heat losses from the gas to cylinder and piston wall [27]. The lowest value of specific fuel consumption is $0.201 \mathrm{~kg} / \mathrm{kWh}$ at $1800 \mathrm{rpm}$. Engine speed plays an important role for the fuel consumption in the engine.

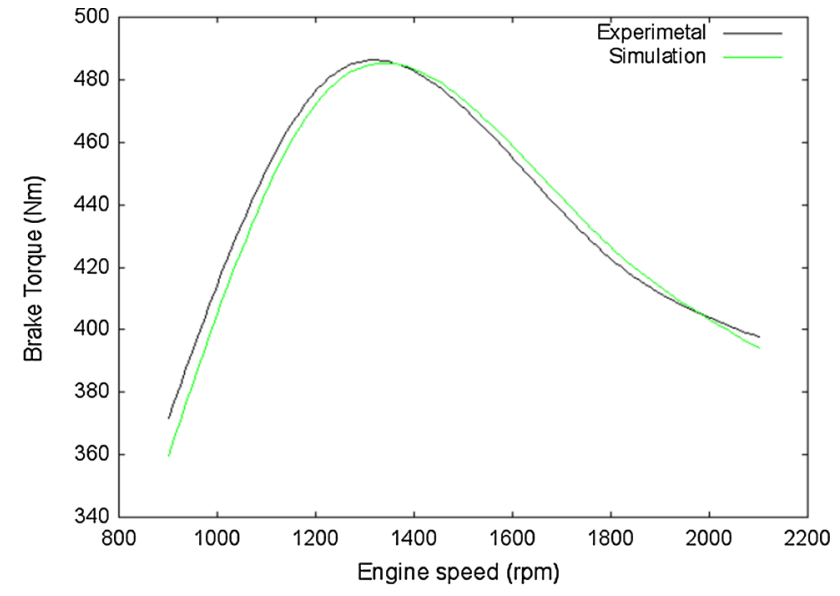

(a) Brake torque

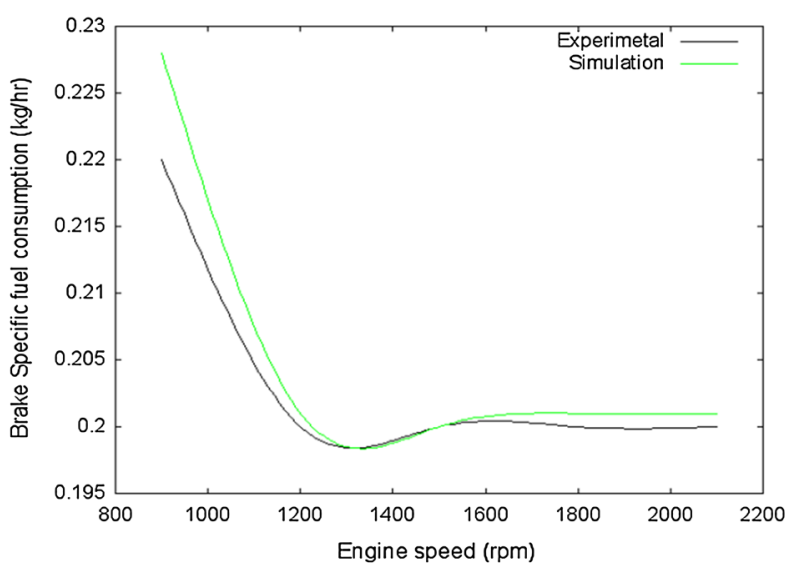

(b) Brake specific fuel consumption (BSFC)

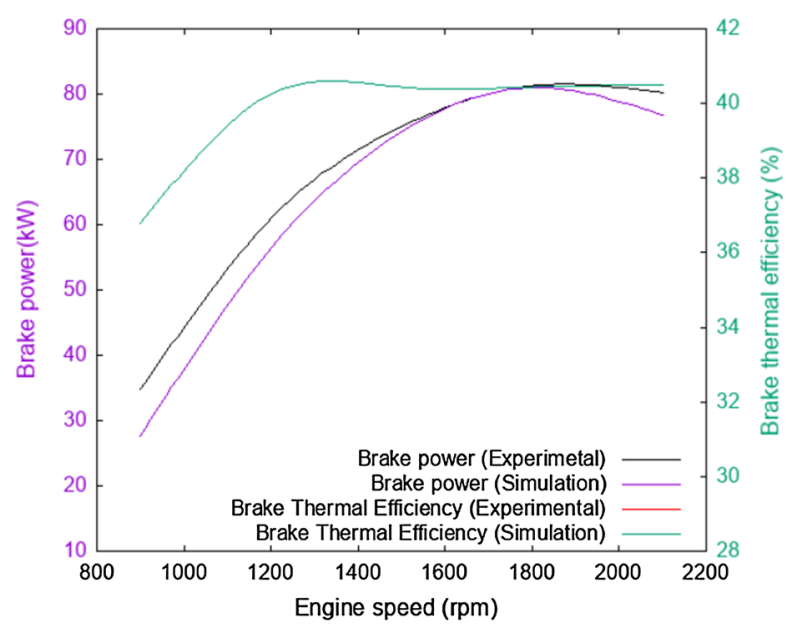

(c) Brake power and brake thermal efficiency

Fig. 3 Validation of simulated values of performance parameters (brake torque, BSFC, brake thermal efficiency and brake power) with experimental data

As the speed increases, the fuel consumption also increases due to increase in friction power, and hence, the efficiency decreases. 
Table 3 Comparison of Ricardo wave results with experimental data for performance parameters

\begin{tabular}{|c|c|c|c|c|c|c|}
\hline \multirow[t]{2}{*}{ Engine speed (rpm) } & \multicolumn{2}{|c|}{ Brake power $(\mathrm{kW})$} & \multicolumn{2}{|c|}{ Brake torque $(\mathrm{Nm})$} & \multicolumn{2}{|l|}{ BSFC (kg/h) } \\
\hline & Experiment & Ricardo & Experiment & Ricardo & Experiment & Ricardo \\
\hline 900 & $34.72 \pm 0.37$ & 27.00 & $371.75 \pm 3.77$ & 360.1 & $0.22 \pm 0.008$ & 0.228 \\
\hline 1200 & $60.92 \pm 1.48$ & 57.50 & $476.45 \pm 2.66$ & 471.1 & $0.20 \pm 0.005$ & 0.201 \\
\hline 1500 & $74.97 \pm 0.60$ & 74.54 & $471.05 \pm 3.37$ & 475.3 & $0.20 \pm 0.0$ & 0.200 \\
\hline 1800 & $81.25 \pm 0.58$ & 79.58 & $422.70 \pm 2.34$ & 425.2 & $0.20 \pm 0.001$ & 0.201 \\
\hline 2100 & $88.42 \pm 0.40$ & 77.52 & $397.72 \pm 2.06$ & 394.49 & $0.20 \pm 0.002$ & 0.201 \\
\hline
\end{tabular}

In the same manner, brake power values predicted by Ricardo wave model at different engine speeds are plotted and a nonlinear regression equation was developed with $R^{2}=0.99$ :

$P=-6 E-05 S^{2}+0.2243 S-124.8$

Figure $3 \mathrm{c}$ shows the variation of brake power and brake thermal efficiency with respect to engine speed. Good agreement is obtained for both the parameters between the simulated and measured values. It is observed that the brake power increases with an increase in engine speed. The maximum power produced by the engine is about $79.58 \mathrm{~kW}$ at around $1800 \mathrm{rpm}$. Brake thermal efficiency initially increases up to $1200 \mathrm{rpm}$, and then it becomes constant.

The quantitative measure of the agreement between the experiment and the simulation is presented in Table 3. It can be noted that Ricardo wave satisfactorily reproduces the experimental data for all the chosen performance parameters. Henceforth, the calibrated wave model is expected to be able to predict the transient behavior of the chosen heavy-duty compression ignition (CI) engine since the Ricardo wave has sufficient prediction capabilities to yield the reliable results for transient simulations.

\subsection{Evaluation of Air Injection}

\subsubsection{Acceleration Tests}

Acceleration tests are best representative of transient operation of heavy-duty engines, and turbo lag is more prominent during the acceleration at low engine speeds. Further, from Fig. 3 it can be noted that the torque performance of turbocharged diesel engine is poor at $1000 \mathrm{rpm}$ engine speed. For these reasons, simulations are performed at $1000 \mathrm{rpm}$ engine speed with and without air injection during the transient conditions of rapid acceleration. During this time, the engine speed is increased from 1000 to $1700 \mathrm{rpm}$. Acceleration time and air injection pressure are the two transient performance factors for which the turbocharger response is measured.

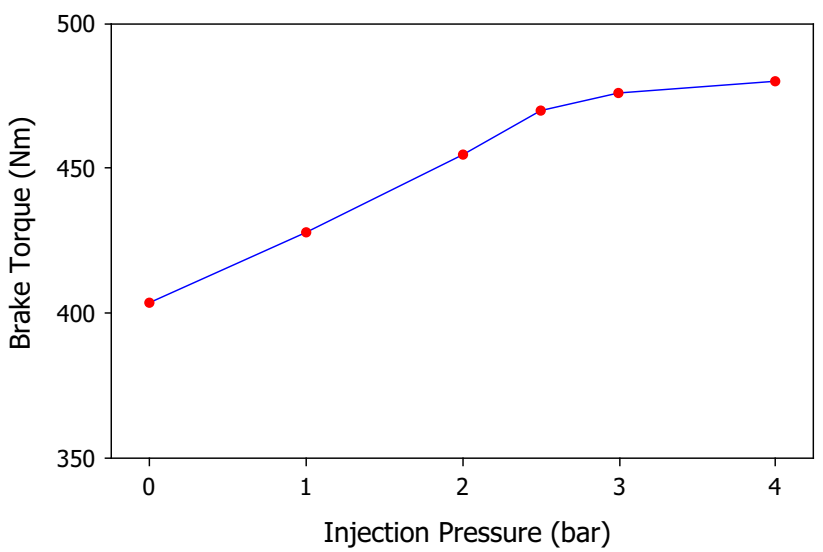

Fig. 4 Variation of brake torque with injection pressure

The time to acceleration is taken as $1 \mathrm{~s}$ and $2 \mathrm{~s}$ as they correspond to the case of rapid acceleration. To analyze the effect of varying the injection pressure, the simulation of air injection is first performed to establish its effect on the engine performance factors. Figures 4 and 5 show that the engine performance factors such as brake torque and brake power have noticed significant improvement with the injection pressure up to 2.5 bar. Increasing the injection pressure after 2.5 bar does not bring significant improvement in these engine performance factors. So the injection pressures of 1 bar, 2 bar and 2.5 bar are chosen to quantify the effect of air injection on the response characteristics of the turbocharger.

The major parameters investigated are the turbocharger response parameters such as compressor exit pressure (CEP), turbine inlet pressure (TIP) and turbine inlet temperature (TIT). These parameters indicate the output response of the turbocharger. So, these are taken as a measure of transient response of the turbocharged engine.

For the sake of studying the effect of acceleration time and injection pressure, three tests are carried out as shown in Table 4 . Test 1 presents the case of no air injection and only the acceleration time is varied by $1 \mathrm{~s}$ and $2 \mathrm{~s}$. Test 2 is taken as the case of more rapid acceleration with the speed change from 1000 to $1700 \mathrm{rpm}$ in $1 \mathrm{~s}$ and the injection pressure is varied by 1 bar, 2 bar and 2.5 bar. Finally, test 3 highlights the comparative improvement in turbo lag reduction for $1 \mathrm{~s}$ and 


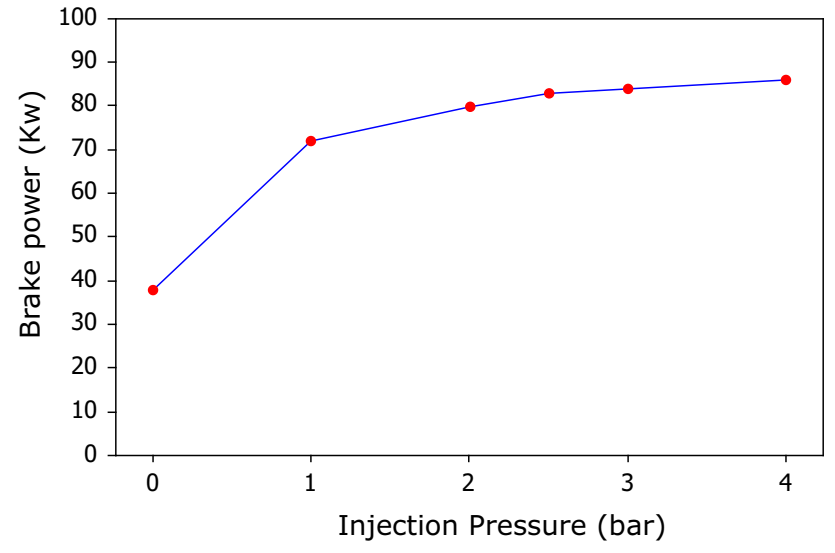

Fig. 5 Variation of brake power with injection pressure

Table 4 Test cases

\begin{tabular}{lll}
\hline Tests & Turbocharger response & \\
\cline { 2 - 3 } & Acceleration time & Air injection pressure \\
\hline Test 1 & Varied & Not applied \\
Test 2 & Constant & Varied \\
Test 3 & Varied & Constant
\end{tabular}

$2 \mathrm{~s}$ injection duration, respectively, for the injection pressure of $2.5 \mathrm{bar}$.

3.2.1.1 Test 1 In the first test, the turbocharger response parameters are observed for the acceleration times of $1 \mathrm{~s}$ and $2 \mathrm{~s}$, respectively, for the speed change from 1000 to $1700 \mathrm{rpm}$. Figure 6 depicts the effect of acceleration time on the response parameters of the turbocharger such as compressor exit pressure (CEP), turbine inlet pressure (TIP) and turbine inlet temperature (TIT). The values are plotted in Fig. 7 for comparative analysis. Similar trends are observed for turbo lag for all the chosen parameters of the turbocharger. For $1 \mathrm{~s}$ acceleration time, the turbo lag values are found to be $6.4 \mathrm{~s}, 6.8 \mathrm{~s}$ and $8.0 \mathrm{~s}$ for CEP, TIP and TIT, respectively. On the other hand, the turbo lag values are $6.0 \mathrm{~s}, 6.0 \mathrm{~s}$ and $6.8 \mathrm{~s}$ for CEP, TIP and TIT, respectively, for $2 \mathrm{~s}$ acceleration time. This indicates that a decrease in time duration for acceleration from 2 to $1 \mathrm{~s}$ increases the turbo lag, and hence, $1 \mathrm{~s}$ corresponds to more rapid acceleration. The finding is consistent with the fact that turbo lag arises due to the delayed response of the turbocharger and the faster is the transient event, comparatively slower will be the response. Based on this finding, $1 \mathrm{~s}$ time duration for acceleration will be considered as the time duration for rapid acceleration for test 2 .

3.2.1.2 Test 2 As per the investigations carried out in test 1 , it should be noted that $1 \mathrm{~s}$ acceleration time corresponds to rapid acceleration for which the improvement in transient performance needs to be measured. So, in this test: The time for acceleration is taken as $1 \mathrm{~s}$ and the effect of air injection

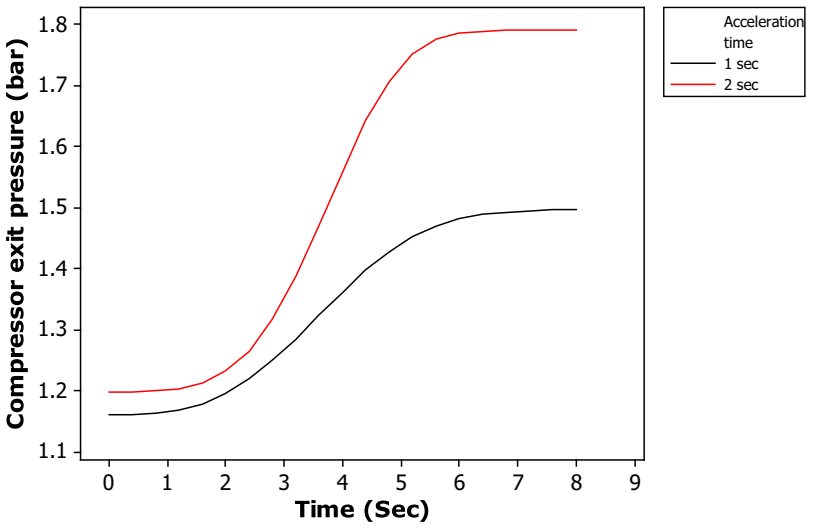

(a) Compressor exit pressure response

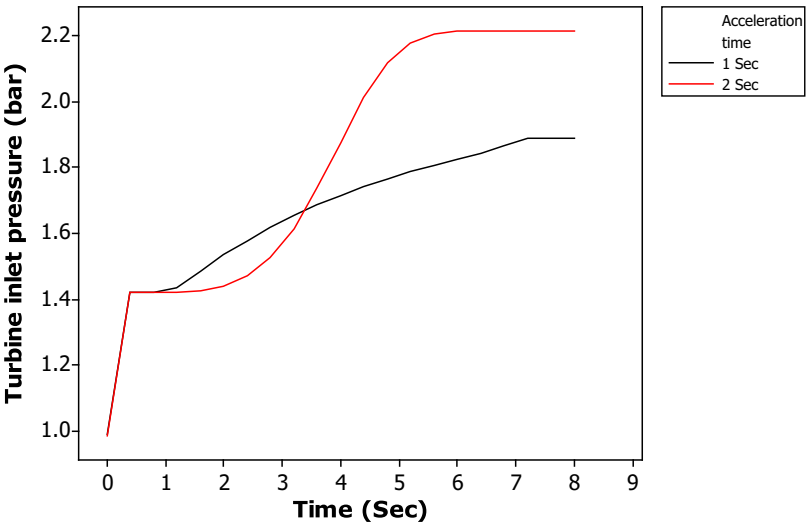

(b) Turbine inlet pressure response

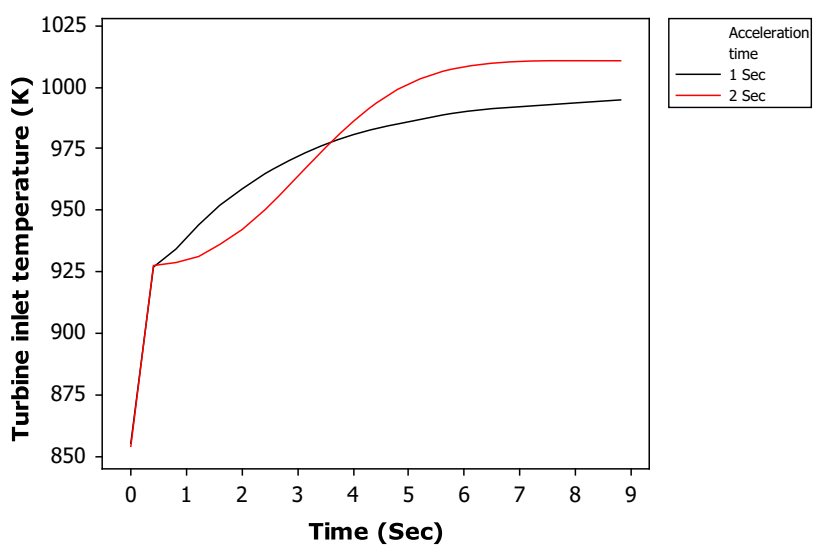

(c) Turbine inlet temperature response

Fig. 6 Effect of acceleration time on response parameters

pressure is measured on turbocharger response parameters such as CEP, TIP and TIT. The cases of additional air injection are compared with that of no injection. In the present investigation, the injection pressures considered are $1 \mathrm{bar}$, 2 bar and 2.5 bar to observe the optimum improvement in transient response.

When additional air is injected at intake manifold, more air is supplied to the cylinder that optimizes the combustion processes. The consequence is the increase in exhaust energy 


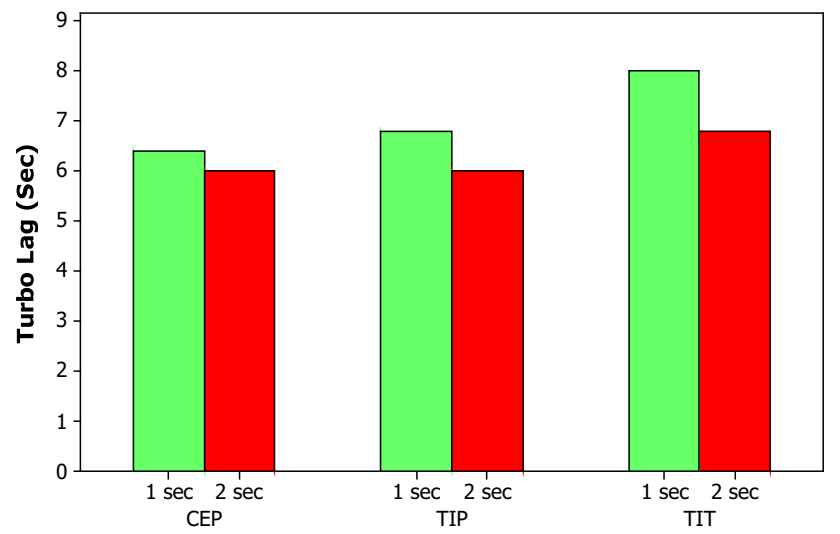

Fig. 7 Variation of response parameters with acceleration time

which in turn increases turbine inlet pressure. This causes the turbocharger to rotate faster yielding improved turbocharger response [1].

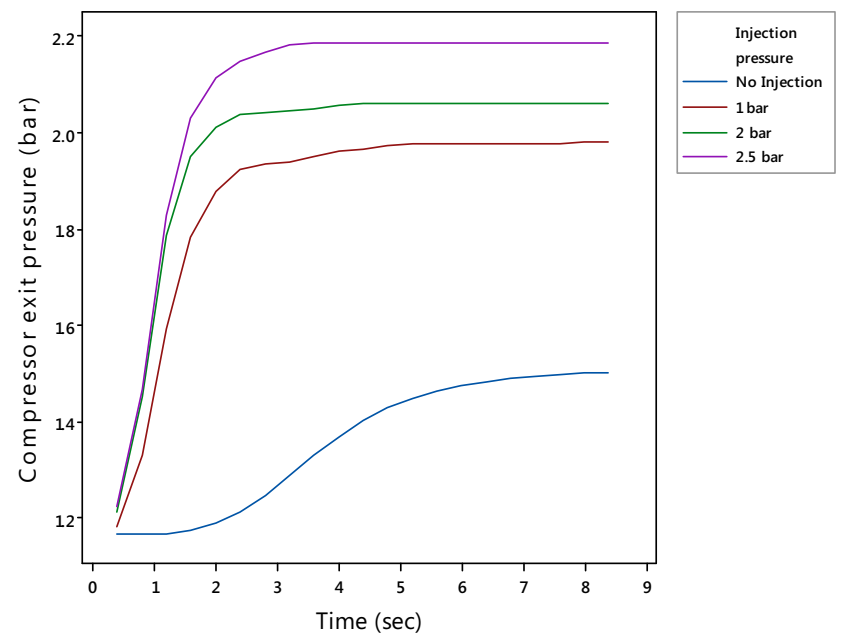

(a) Compressor exit pressure response
The effect of air injection is noticeable as shown in Fig. 8. Initially, the parameters show an initial delay in response before reaching the steady state. The recovery time is significantly reduced as compared to that of no air injection for all the parameters. Turbo lag decreases, and the final steady-state values are also improved with the increase in air injection pressure. The comparative reduction in turbo lag with varied air injection pressure for each parameter is shown in Fig. 9.

Although each of the selected injection pressure is sufficient to improve the transient performance as shown in Fig. 8, nevertheless it is important to find the optimum value of the injection pressure. So, in addition to the performance improvement evaluation with air injection, it is worth calculating that how much energy is imparted with the air injection. Turbo lag reduction with minimum energy required by air injection will be an additional source of information for selecting the optimum injection pressure.

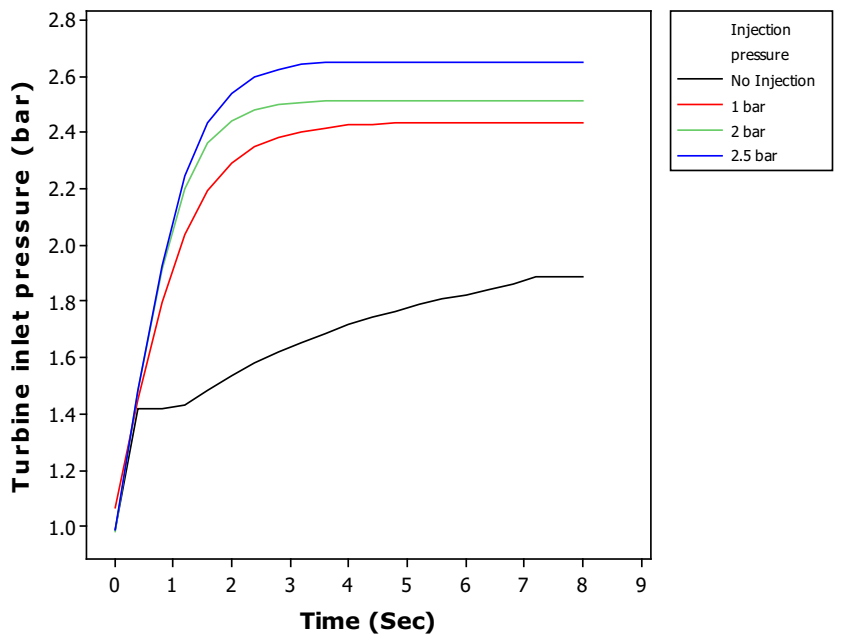

(b) Turbine inlet pressure response

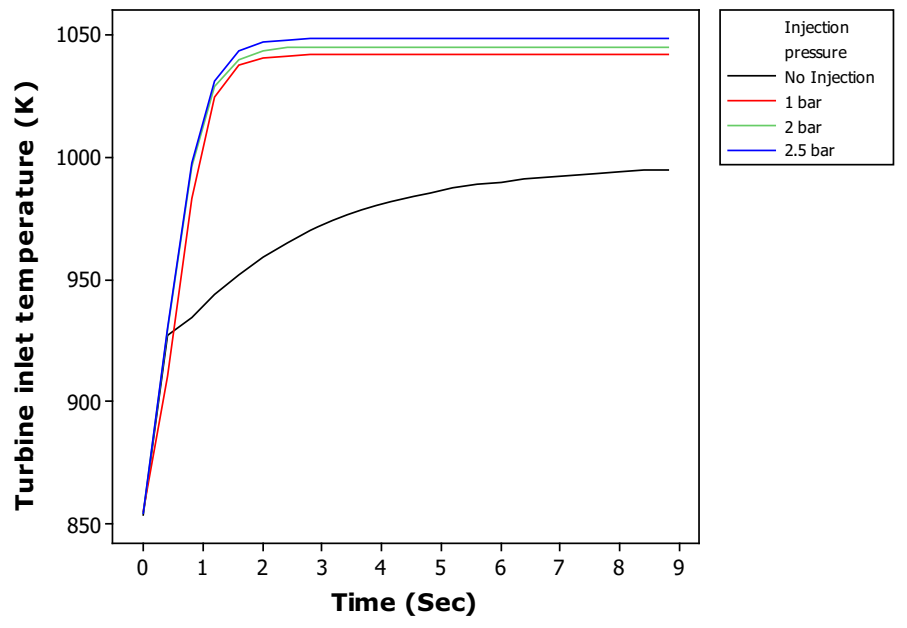

(c) Turbine inlet temperature response

Fig. 8 Effect of air injection pressures on response parameters (CEP, TIP and TIT) 


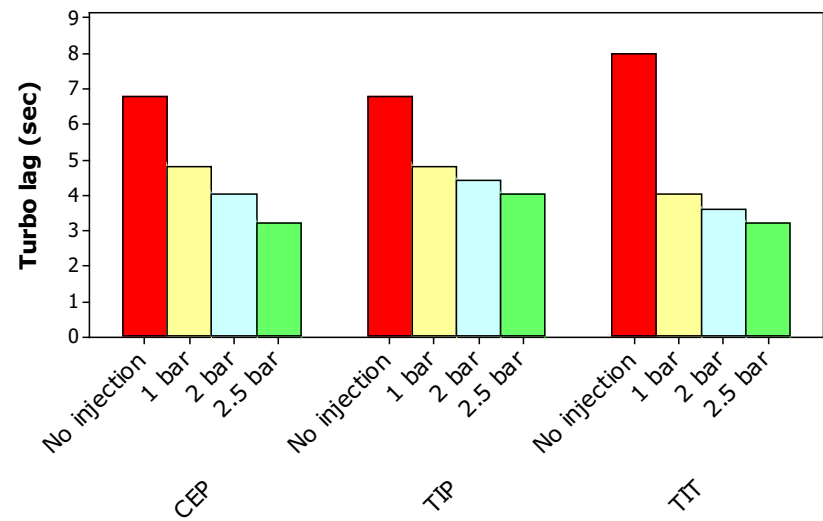

Fig. 9 Variation of response parameters with air injection pressures for turbo lag

Figure 10 shows the reliance of turbo lag reduction on air assist pressure and in turn the energy required for each of
Table 5 Turbo lag reduction per unit energy corresponding to air injection pressure for turbocharger response parameters (CEP, TIP and TIT)

\begin{tabular}{llll}
\hline $\begin{array}{l}\text { Injection } \\
\text { pressure (bar) }\end{array}$ & \multicolumn{4}{l}{ Turbo lag reduction per unit energy } \\
\cline { 2 - 4 } & CEP & TIP & TIT \\
\hline 1 & 0.290 & 0.392 & 0.555 \\
2 & 0.102 & 0.122 & 0.146 \\
2.5 & 0.032 & 0.034 & 0.040 \\
\hline
\end{tabular}

the selected performance parameter. Higher the injection pressure, more energy is required to significantly reduce the turbo lag. For comparative analysis, the turbo lag reduction per unit energy corresponding to the injection pressure is presented in Table 5. It can be concluded from the table that the maximum improvement in turbo lag reduction is brought by air injection corresponding to 1 bar pressure.

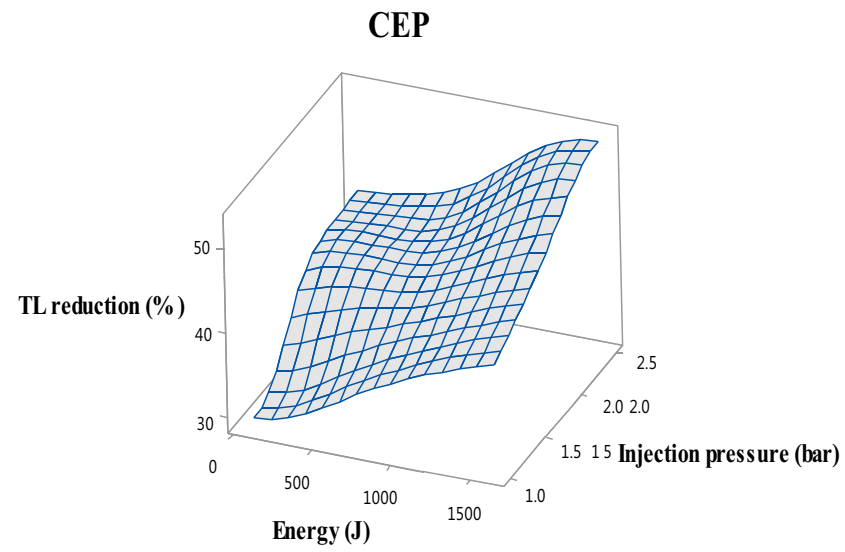

(a) Compressor exit pressure

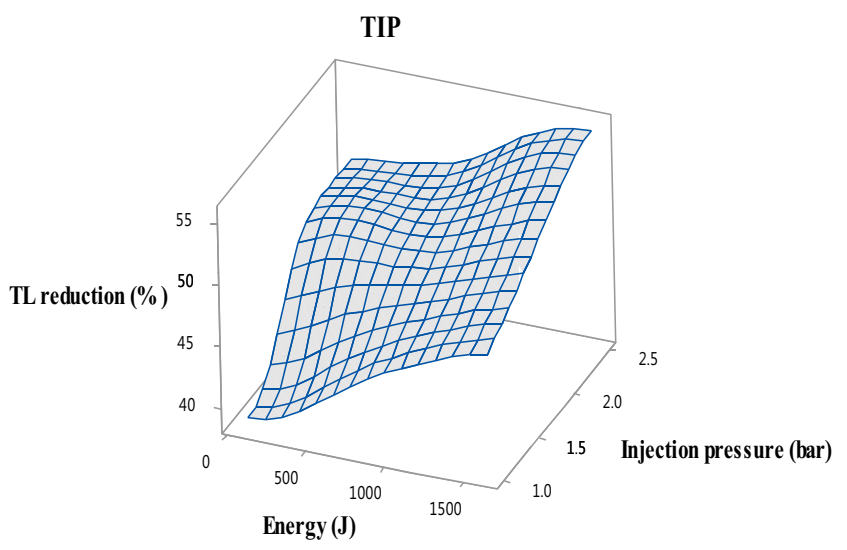

(b) Turbine inlet pressure

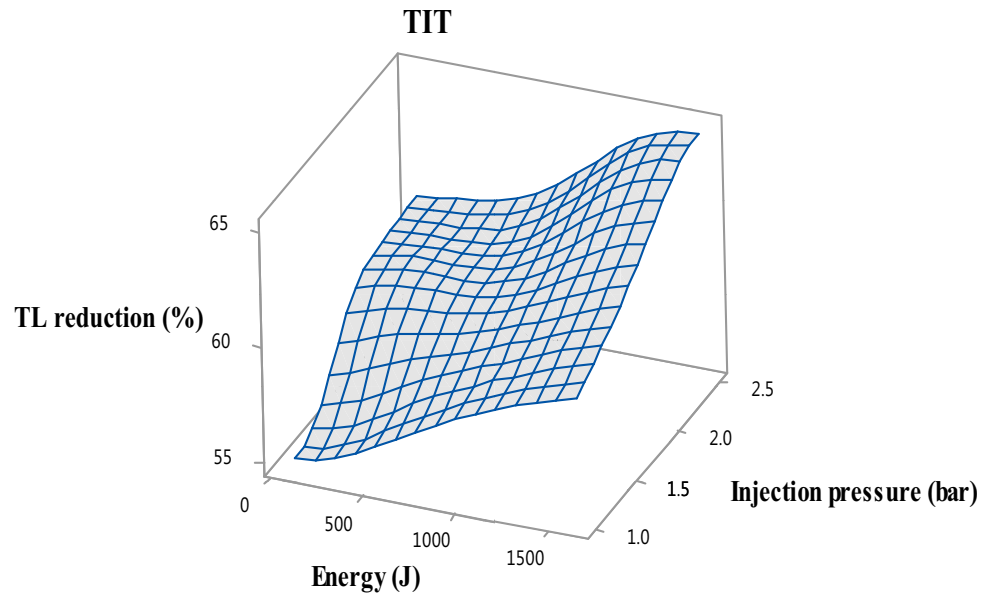

(b) Turbine inlet temperature

Fig. 10 Dependency of turbo lag reduction on air-supply parameters for CEP, TIP and TIT 


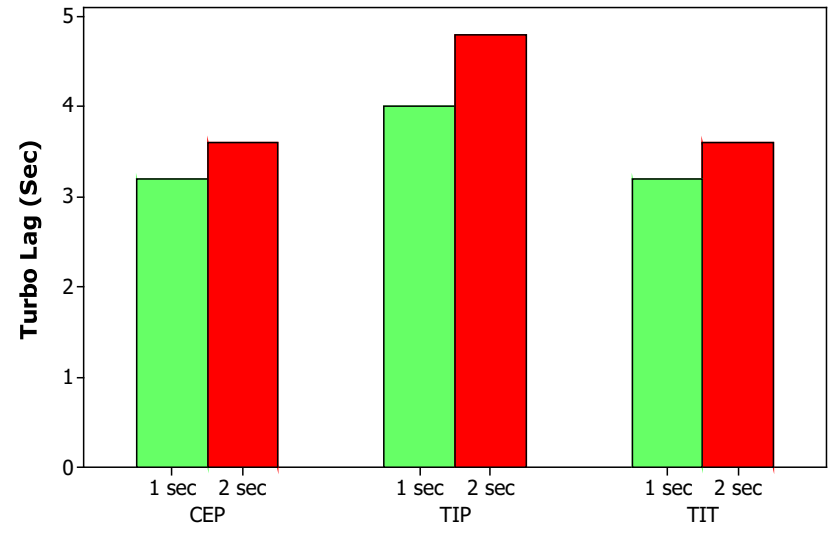

Fig. 11 Effect of air injection on response parameters with variable acceleration time

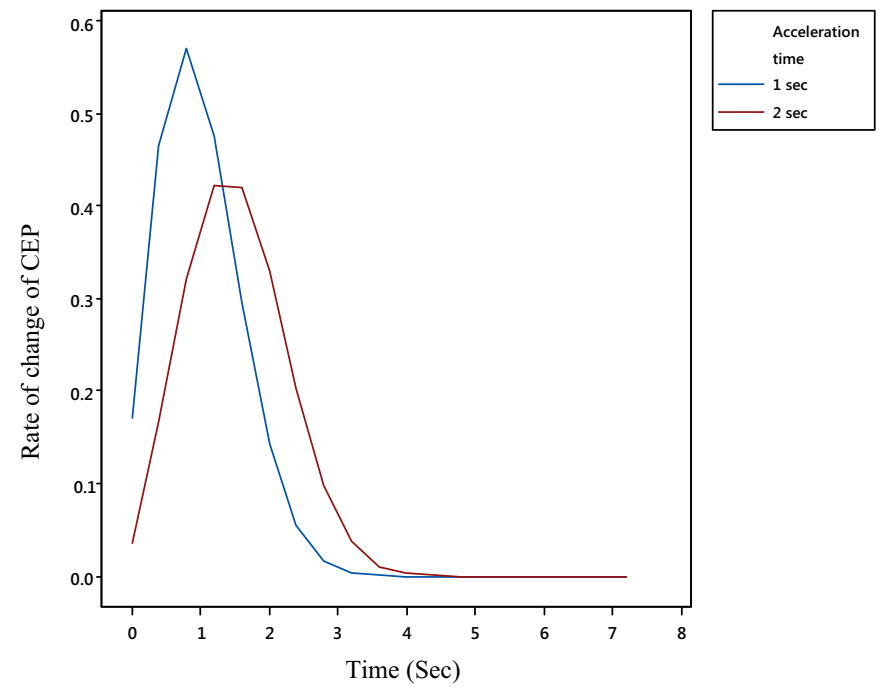

(a) Compressor exit pressure
Hence, 1 bar air injection is the optimum injection pressure with turbo lag reduction (in fraction) per unit energy as 0.290 , 0.392 and 0.555 per Joule for compressor exit pressure, turbine inlet pressure and turbine inlet temperature (TIT), respectively.

3.2.1.3 Test 3 In this test, 1 bar pressure is taken as the optimum injection pressure as found in test 2 . The response characteristics are observed for acceleration time of $1 \mathrm{~s}$ and $2 \mathrm{~s}$, respectively, for the speed change from 1000 to $1700 \mathrm{rpm}$ as shown in Fig. 11. As per the comparative analysis illustrated in Fig. 11, the turbo lag quantification for the air injection of 1 bar highlights a remarkable reduction in turbo lag for $1 \mathrm{~s}$ transient as compared to that of $2 \mathrm{~s}$ and this differ-

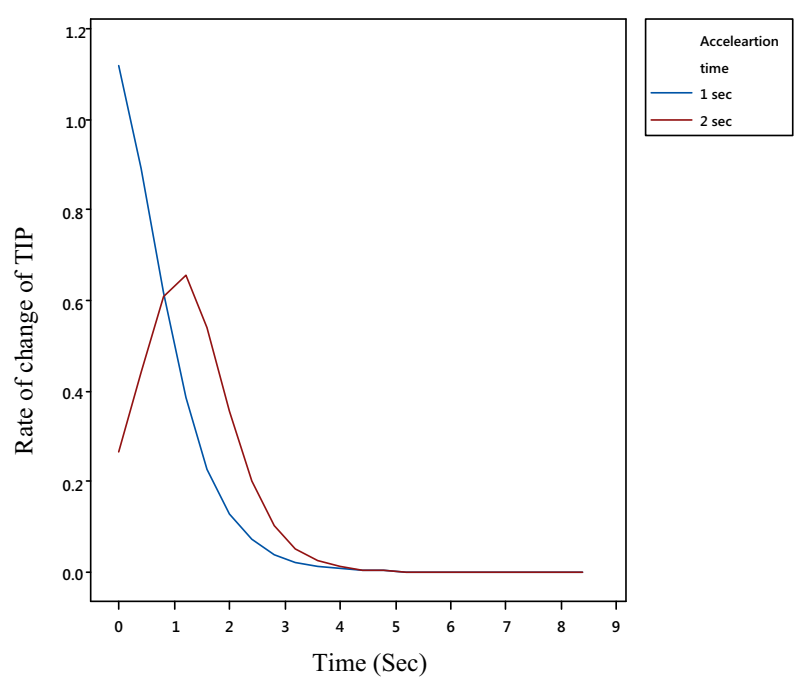

(b) Turbine inlet pressure

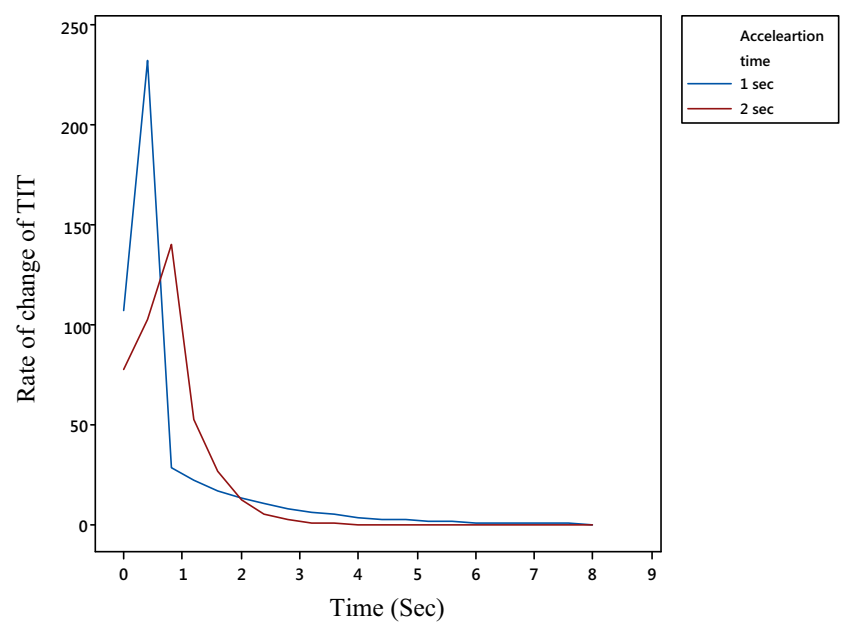

(c) Turbine inlet temperature

Fig. 12 Rate of change characteristics for response parameters (CEP, TIP and TIT) 
ence is more perceptible when the rate of change in response parameters is plotted as shown in Fig. 12.

The figure shows that faster response is observed for $1 \mathrm{~s}$ duration when air injection is applied. Hence, more improvement is achieved where the turbo lag is more prominent (that is for $1 \mathrm{~s}$ acceleration time as reported in test 1 ). This ensures that the air injection at intake manifold greatly improves the transient response of turbocharged diesel engine for the event of rapid acceleration.

\section{Conclusions}

In the present study, the real engine is modeled using Ricardo wave simulation software; and after validation using the steady-state simulations, the transient performance of the turbocharged diesel engine is investigated. Air injection at intake manifold is simulated to improve the transient response. Based on the results obtained from this study, the following conclusions are drawn for this specific heavy-duty diesel engine:

1. With air injection system, the response interval of the turbocharger is significantly reduced.

2. The turbocharger response parameters such as compressor exit pressure (CEP), turbine inlet pressure (TIP) and turbine inlet temperature (TIT) increase with the increase in air injection pressure and 2.5 bar injection pressure brings the maximum improvement in the transient response.

3. The amount of energy imparted for air injection should not be neglected while evaluating the effectiveness in reducing the turbo lag for the improvement in transient response. Greater reduction in turbo lag can be achieved by applying higher assist pressure up to 2.5 bar but at the cost of compromised energy imparted per second.

4. 1 bar is the optimum injection pressure with turbo lag reduction per unit energy as $29.0 \%, 39.2 \%$ and $55.5 \%$ per Joule for compressor exit pressure, turbine inlet pressure and turbine inlet temperature (TIT), respectively.

5. Turbo lag is more prominent when the acceleration time is $1 \mathrm{~s}$ than that for $2 \mathrm{~s}$. With the application of air injection, faster recovery time is observed for $1 \mathrm{~s}$ rapid acceleration than that of $2 \mathrm{~s}$.

The study demonstrates that additional air injection at intake manifold is an effective tool for achieving the improvement in the transient response of heavy-duty turbocharged diesel engine.

Open Access This article is distributed under the terms of the Creative Commons Attribution 4.0 International License (http://creativecomm ons.org/licenses/by/4.0/), which permits unrestricted use, distribution, and reproduction in any medium, provided you give appropriate credit to the original author(s) and the source, provide a link to the Creative Commons license, and indicate if changes were made.

\section{References}

1. Wei, F.: A Study on the Improvement of Marine Diesel Engine Transient Performance by Means of Air Injection. HKU Theses Online (HKUTO) (2005)

2. Tesfa, B.; Mishra, R.; Zhang, C.; Gu, F.; Ball, A.D.: Combustion and performance characteristics of CI (compression ignition) engine running with biodiesel. Energy 51, 101.B-115.B (2013)

3. Tesfa, B.; Gu, F.; Mishra, R.; Ball, A.D.: LHV predication models and LHV effect on the performance of CI engine running with biodiesel blends. Energy Convers. Manag. 71, 217-226 (2013)

4. Zhao, D.; Winward, E.; Yang, Z.; Stobart, R.; Steffen, T.: Characterisation, control, and energy management of electrified turbocharged diesel engines. Energy Convers. Manag. 135, 416-433 (2017)

5. Tesfa, B.; Mishra, R.; Gu, F.; Ball, A.D.: Water injection effects on the performance and emission characteristics of a CI engine operating with biodiesel. Renew. Energy 37(1), 333-344 (2012)

6. Taylor, A.M.: Science review of internal combustion engines. Energy Policy 36(12), 4657-4667 (2008)

7. Liu, Q.; Liu, Z.; Han, Y.; Tian, J.; Wang, J.; Fang, J.: Experimental investigation of the loading strategy of an automotive diesel engine under transient operation conditions. Energies 11(5), 1293 (2018)

8. Mishra, R.; Saad, S.M.: Simulation based study on improving the transient response quality of turbocharged diesel engines. J. Qual. Maint. Eng. 23(3), 297-309 (2017)

9. Yum, K.K.; Lefebvre, N.; Pedersen, E.: An experimental investigation of the effects of cyclic transient loads on a turbocharged diesel engine. Appl. Energy 185, 472-481 (2017)

10. Serrano, J.R.; Arnau, F.J.; Dolz, V.; Piqueras, P.: Methodology for characterisation and simulation of turbocharged diesel engines combustion during transient operation. Part 1: data acquisition and post-processing. Appl. Therm. Eng. 29(1), 142-149 (2009)

11. Han, Y.; Zhang, L.; Liu, Z.; Tian, J.: Investigation of transient deterioration mechanism and improved method for turbocharged diesel engine. Energy 116, 250-264 (2016)

12. Vafaie, M.H.; Dehkordi, B.M.; Moallem, P.; Kiyoumarsi, A.: A new predictive direct torque control method for improving both steady-state and transient-state operations of the PMSM. IEEE Trans. Power Electron. 31(5), 3738-3753 (2016)

13. Khalek, I.A.; Spears, M.; Charmley, W.: Particle Size Distribution from a Heavy-Duty Diesel Engine: Steady-State and Transient Emission Measurement Using Two Dilution Systems and Two Fuels (No. 2003-01-0285). SAE Technical Paper (2003)

14. Lee, C.S.; Choi, N.J.: Effect of air injection on the characteristics of transient response in a turbocharged diesel engine. Int. J. Therm. Sci. 41(1), 63-71 (2002)

15. Gilkes, O.S.; Mishra, R.: Comparison of Passive and Active Methods for Improving Transient Performance of Turbocharged Engine Systems. University of Huddersfield, Huddersfield (2006)

16. Gilkes, O.S.; Mishra, R.; Rao, H.V.; Fieldhouse, J.D.: Transient Response of Turbocharged Diesel Engine for Transient Operation Using Air Injection Assist System. University of Huddersfield, Huddersfield (2007)

17. Dean, C.S.I.: Novel Configuration for Air Flow Rationalization and Turbo Lag Reduction in CRDI Engine (2012)

18. Cieslar, D.: Control for Transient Response of Turbocharged Engines (Doctoral dissertation, University of Cambridge) (2013) 
19. Giakoumis, E.G.; Tziolas, V.: Modeling a variable-geometry turbocharged diesel engine under steady-state and transient conditions. J. Energy Eng. 144(3), 04018017 (2018)

20. Rakopoulos, C.D.; Dimaratos, A.M.; Giakoumis, E.G.: Investigation of turbocharged diesel engine operation, exhaust emissions, and combustion noise radiation during starting under cold, warm, and hot conditions. Proc. Inst. Mech. Eng. D J. Automob. Eng. 225(9), 1118-1133 (2011)

21. Zare, A.; Bodisco, T.A.; Nabi, M.N.; Hossain, F.M.; Ristovski, Z.D.; Brown, R.J.: Engine performance during transient and steadystate operation with oxygenated fuels. Energy Fuels 31(7), 75107522 (2017)

22. Zare, A.; Bodisco, T.A.; Nabi, M.N.; Hossain, F.M.; Ristovski, Z.D.; Brown, R.J.: A comparative investigation into cold-start and hot-start operation of diesel engine performance with oxygenated fuels during transient and steady-state operation. Fuel 228, 390404 (2018)

23. Ricardo WAVE knowledge center help files, Diesel: Combustion Data
24. Tesfa, B.; Gu, F.; Mishra, R.; Ball, A.: Emission characteristics of a $\mathrm{CI}$ engine running with a range of biodiesel feedstocks. Energies 7(1), 334-350 (2014)

25. Tesfa, B.; Mishra, R.; Gu, F.S.; Ball, A.: Condition monitoring of CI engine running on biodiesel using transient process. In: Key Engineering Materials, Vol. 413, pp. 495-503. Trans Tech Publications (2009)

26. Brito, I.H.: Modeling and Control of Wastegate Equipped Turbocharged Engines (2010). http://digitalrepository.unm.edu/me_ etds $/ 44$

27. http://www.iitg.ernet.in/scifac/qip/public_html/cd_cell/chapters/ uk_saha_internal_combustion_engine/qip-ice-05-engine \%20efficiencies.pdf. Date of Access 23 May 2017 